\section{THU0580 JOINT MANIFESTATIONS SECONDARY TO IMMUNOTHERAPY: CLINICAL CHARACTERISTICS AND EVOLUTION}

Carolina Perez-Garcia ${ }^{1}$, Fabiola Ojeda ${ }^{1}$, Ana Pros Simón ${ }^{1}$, Emma Beltrán ${ }^{1}$, Tarek Carlos Salman Monte ${ }^{1}$, Edurne Arriola Aperribay ${ }^{2}$, Jordi Monfort ${ }^{1} .{ }^{1}$ Hospital del Mar, Rheumatology, Barcelona, Spain; ${ }^{2}$ Hospital del Mar, Oncology, Barcelona, Spain

Background: Inhibitors of CTLA-4 and PD-1 have shown improvements in survival in multiple advanced cancers. Immune-mediated effects such as arthralgias and arthritis have been described, but their prevalence and characteristics have not been well defined.

Objectives: The objective of the study is to describe the prevalence of immunomediated joint manifestations (IJM), its characteristics and evolution in patients who received immunotherapy (nivolumab (NV), pembrolizumab (PB)) from January 1, 2016 to December 31, 2018 in our center.

Methods: Data collection was performed at through the RPT (Registre Pacients Tractats) database of the CatSalut, and the patients referred to the monographic medical office of inflammatory joint diseases of our center. In all cases, the variables: age, sex, neoplasia, drug, number of doses, were recorded. In patients with joint involvement: other autoimmune manifestations, joint affectation prior to treatment, delay rheumatology derivation, joint affectation type, swollen and tender joint counts, ESR, CRP, RF, ACPA, ANA, HLA B 27, Hb, leukocytes, neutrophils, lymphocytes, treatment and evolution, were recorded. The statistical analysis was carried out with the SPSS 15.0 computer package

Results: 106 patients received treatment (TTO) with immunotherapy (71 $\mathrm{NV}, 35 \mathrm{BP}$ ) for neoplasia (81 lung, 10 renal, 8 melanoma, 2 orophar$y n x)$. The mean age was $67.93 \pm 10.7$ years $(21.7 \%$ women, $78.3 \%$ men). There were 11 events cataloged as IJM. The overall prevalence was $10.3 \%(5.6 \% \mathrm{NV}, 14.3 \% \mathrm{~PB})$. Patients with IJM received a greater number of doses $(17.67 \pm 9.3$ vs9.24 $\pm 10.1 p=0.018)$. No patient with melanoma presented IJM. All IJM suspicions cases were assessed by a rheumatology. When studying their characteristics (Table 1), 3 patients were added from the database of the rheumatology service (14 cases). They received in a clinical trial BP29541 (rectal cancer), Atezolizumab (lung cancer) and Durvalumab (lung cancer). $42.9 \%$ of the patients presented inflammatory arthralgias (IAT) and $57.1 \%$ arthritis (AT). In reference to their previous history, 2 patients had a history of hyperuricemia and arthritis. One patient concomitantly presented lymphocytic colitis confirmed by biopsy. The delay time for assessment by rheumatology was $18.1 \pm 22.1$ days. Patients with AT were older $(p=0.014)$, had higher ESR $(p=0.047)$ than those with IAT. No differences were found in other variables (table1). With reference to the analytical study, 1 patient was $\mathrm{RF}+, 2$ ANA + at mean titers (1/160-1/320), none ACPA or HLA B 27 +. After assessment by rheumatology, two patients with IAT were diagnosed with bone M1 and two AT were categorized as gouty arthritis. The rest of the IAT responded to NSAIDs, did not require corticosteroids and were resolved. 6 cases of AT received prednisone, 3 required treatment dose $1 \mathrm{mg} / \mathrm{kg}$ weight and subsequently MTX in 2 of them, with evolution to low disease activity at present. Only one patient met RA classification criteria.

Conclusion: The prevalence of IJM was higher than $10 \%$, depending on the number of doses. Patients with arthritis had higher age and higher ESR. No patient presented ACPA and HLA B $27+$, so to include them in the initial analytical could be not necessary. In these patients, it is important the assessment by a rheumatologist to make a correct differential diagnosis, as well as establish referral circuits to avoid delay of care

\begin{tabular}{lccr}
\hline & ARTRHITIS (AT) & ARTHRALGIA (IAT) & P value \\
\hline Age & $71 \pm 6,0$ & $59,3 \pm 9,7$ & $\mathbf{0 , 0 1 4}$ \\
Swollen joints & $3,63 \pm 3,4$ & 0 & $\mathbf{0 , 0 2 6}$ \\
Painful joints & $10,75 \pm 15,7$ & $10,0 \pm 8,7$ & 0,919 \\
ESR & $39,5 \pm 25,3$ & $9,0 \pm 4,3$ & $\mathbf{0 , 0 4 7}$ \\
CRP (mg/dl) & $15,6 \pm 11,6$ & $5,0 \pm 8,8$ & 0,156 \\
Leukocytes $\left(\mathrm{cel} \times 10^{3}\right)$ & $11.026,2 \pm 3264,2$ & $8.156 \pm 3.357,6$ & 0,134 \\
Lymphocytes $\left(\mathrm{cel} \times 10^{3}\right)$ & $1.696,2 \pm 1042,8$ & $1.836,6 \pm 1.188,4$ & 0,818 \\
Neutrofilos $\left(\mathrm{cel} \times 10^{3}\right)$ & $8263,7 \pm 2.668$ & $5.523,6 \pm 3.531$ & 0,123 \\
$\mathrm{Hb}(\mathrm{mg} / \mathrm{dl})$ & $10,8 \pm 2,1$ & $12,1 \pm 2,64$ & 0,325 \\
\hline
\end{tabular}

Disclosure of Interests: Carolina Perez-Garcia: None declared, Fabiola Ojeda: None declared, Ana Pros Simón: None declared, Emma Beltrán: None declared, Tarek Carlos Salman Monte: None declared, Edurne Arriola Aperribay: None declared, Jordi Monfort Speakers bureau: Bioibérica

Procare Health

DOI: 10.1136/annrheumdis-2019-eular.4300

\section{THU0581 BIOLOGICAL THERAPY IN NON ISCHAEMIC OPTIC NEURITIS ASSOCIATED TO IMMUNE-MEDIATED INFLAMMATORY DISEASES. MULTICENTER STUDY}

D. Prieto-Peña ${ }^{1}$, Monica Calderón-Goercke ${ }^{1}$, Vanesa Calvo-Río ${ }^{1}$, Olga MaizAlonso $^{2}$, Ana Blanco ${ }^{2}$, J. Narváez ${ }^{3}$, Santos Castañeda ${ }^{4}$, Esther Vicente ${ }^{4}$, Susana Romero-Yuste ${ }^{5}$, Rosalía Demetrio-Pablo ${ }^{1}$, Ana Urruticoechea-Arana ${ }^{6}$, José L. García-Serrano ${ }^{7}$, Jose Luis Callejas-Rubio ${ }^{7}$, Norberto Ortego ${ }^{7}$, Miguel A González-Gay ${ }^{8}$, Julio Sánchez ${ }^{1}$, Ricardo Blanco ${ }^{1} .{ }^{1}$ Marqués de Valdecilla University Hospital, Santander, Spain; ${ }^{2}$ Ospitalea, San Sebastián, Spain; ${ }^{3}$ Hospital Universitari de Bellvitge, L'Hospitalet de Llobregat, Spain; ${ }^{4}$ Hospital de La Princesa, Madrid, Spain; ${ }^{5}$ Hospital Pontevedra, Pontevedra, Spain; ${ }^{6}$ Hospital Can Misses, Eivissa, Spain; ${ }^{7}$ San Cecilio University Hospital, Granada, Spain; ${ }^{8}$ University Hospital 12 de Octubre, Madrid, Spain

Background: Non ischaemic optic neuritis (NION) is a severe inflammation of the optic nerve that may lead to blindness. It can be primary or associated to immune mediated inflammatory diseases (IMIDs). The treatment of the NION is based on systemic corticosteroids and conventional immunosuppressive drugs.

Objectives: To assess the efficacy of the biological treatment in refractory NION to conventional treatment.

Methods: Multicenter study of 12 patients diagnosed with NION refractory to systemic corticosteroids and at least one conventional immunosuppressive drug. The main outcomes were visual acuity (VA) and optical coherence tomography (OCT) of the optic nerve and the ganglionar cells. Comparisons were made between baseline and the $1^{\text {st }}$ week, $1^{\text {st }}$ and $6^{\text {th }}$ month and $1^{\text {st }}$ year. (STATISTICA, StatSoft Inc. Tulsa, Oklahoma, USA). Results: We studied 12 patients (19 affected eyes) (5 men/7 women); mean age of $29.8 \pm 12.9$ years. The underlying diseases were systemic lupus erythematosus $(n=1)$, neuromyelitis optica $(n=1)$, neuroretinitis $(n=1)$, relapsing polychondritis $(n=1)$, pars planitis $(n=1)$, Behçet's disease $(n=2)$ and idiopathic $(n=5)$. Before biological treatment and besides oral corticosteroids, patients had received intravenous (IV) methylprednisolone boluses $(n=9)$, cyclosporine $A(n=1)$, cyclophosphamide $(n=2)$, mycophenolate $(n=2)$, hydroxychloroquine $(n=1)$, methotrexate $(n=8)$ and azathioprine $(n=5)$. Biological treatment was bases on rituximab $(n=2)$ (2 IV, doses of 1 g/every 2 weeks and every 6 moths), adalimumab ( $n=5)$ (40 mg/1-2 week), tocilizumab ( $\mathrm{n}=4)(8 \mathrm{mg} / \mathrm{kg} / 2-4$ weeks) and infliximab $(\mathrm{n}=3)(5 \mathrm{mg} /$ $\mathrm{kg}$ at 0,2 and 6 week and then every 8 weeks). The characteristics of the 12 patients are shown in the TABLE.

After biological treatment we observed an improvement in the ocular parameters: VA $[0.66 \pm 0.32$ to $0.84 \pm 0.29 ; p=0.03]$, OCT of the optic nerve [123.20 \pm 58.28 to $190.54 \pm 175.38 ; p=0.11]$, and OCT of the ganglionar cells [369.55 \pm 137.37 to $270.67 \pm 23.21 ; p=0.03]$ at one year. After a mean follow-up of $29.09 \pm 19.23$ months, there were no severe adverse effects. Conclusion: Biologic therapy in NION idiopathic or associated to IMIDs, refractory to conventional treatment, seems to be effective.

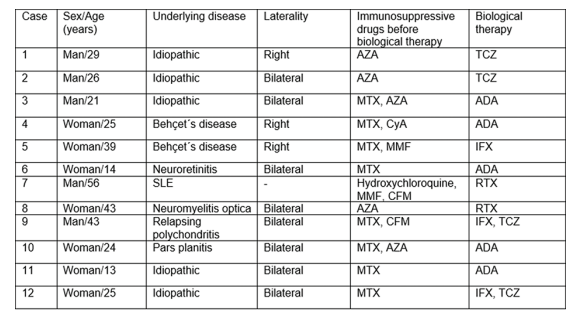

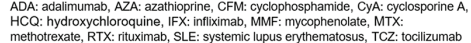

Disclosure of Interests: D. Prieto-Peña: None declared, Monica CalderónGoercke: None declared, Vanesa Calvo-Río: None declared, Olga Maiz Alonso Speakers bureau: Pfizer, Ana Blanco: None declared, J. Narváez Consultant for: Bristol-Myers Squibb, Santos Castañeda Consultant for: Amgen, BMS, Pfizer, Lilly, MSD, Roche, Sanofi, UCB, Esther Vicente: None declared, Susana Romero-Yuste: None declared, Rosalía DemetrioPablo: None declared, ANA URRUTICOECHEA-ARANA: None declared, José L. García-Serrano: None declared, Jose Luis Callejas-Rubio: None declared, Norberto Ortego: None declared, Julio Sánchez: None declared, Miguel A González-Gay Grant/research support from: Prof. MA GonzalezGay received grants/research supports from Abbvie, MSD, Jansen and Roche., Speakers bureau: Consultation fees/participation in company sponsored speaker's bureau from Pfizer, Lilly, Sobi, Celgene, Novartis, Roche and Sanofi., Ricardo Blanco Grant/research support from: Abbvie, MSD, and Roche, Consultant for: Abbvie, Pfizer, Roche, Bristol-Myers, Janssen, Speakers bureau: Abbvie, Pfizer, Roche, Bristol-Myers, Janssen

DOI: 10.1136/annrheumdis-2019-eular.3615 


\section{THU0582 THE TNF RECEPTOR-ASSOCIATED PERIODIC SYNDROME (TRAPS): CLINICAL AND GENETIC CHARACTERIZATION OF A COHORT OF ADULTS DIAGNOSED OF TRAPS SYNDROME}

Alberto Ruiz Román ${ }^{1}$, Salvador García Morillo², Marco Montes Cano ${ }^{3}$, Clara Aguilera $\mathrm{Cros}^{1}$, Manuel Leon Luque ${ }^{1}$, Maria Jose Valenzuela Porcel ${ }^{1}$, Maria Arcila Duran ${ }^{1}$, Lara Mendez ${ }^{1}$, Isabel Madroñal García ${ }^{1} .{ }^{1}$ HOSPITAL VIRGEN DEL ROCIO, Rheumatology, Seville, Spain; ${ }^{2}$ HOSPITAL VIRGEN DEL ROCIO, Internal Medicine, Seville, Spain; ${ }^{3}$ HOSPITAL VIRGEN DEL ROCIO, Immunology, Seville, Spain

Background: Tumor necrosis factor receptor-associated periodic syndrome (TRAPS) is a disease that is included within of hereditary syndromes of periodic fever. It presents an autosomal dominant pattern of inheritance. It's due to mutations of TNFRSF1A gene. It is usually present in childhood although it can also appear in adulthood and it tends to cause high levels of acute phase reactants, fever, musculoskeletal symptoms (myalgias, arthralgias, arthritis), rash, abdominal pain, etc

Objectives: To describe the clinical characteristics and genetic variants of patients diagnosed with TRAPS syndrome in a cohort of patients with autoinflammatory syndromes with follow-up in a tertiary hospital from 2013 to the present

Methods: Retrospective descriptive study of adult patients diagnosed with autoinflammatory syndrome since 2013 (year of introduction of genetic tests in the hospital laboratory) until now. The data was obtained from the review of medical records. All patients with mutations in TNRFSF1A gene and clinically compatible with this diagnosis were reviewed

Results: Of a total of 44 adult patients diagnosed with hereditary syndromes of periodic fever (FMF, TRAPS, cryopyrinopathies, HIDS) and compatible genetic mutations (excluding polymorphisms), 13 (29.5\%) presented mutations in the TNFRSF1A gene. Of those 13 patients, 9 $(69.2 \%)$ were women. The most frequent mutations were the mutation in heterozygosis in exon 4 (p.R92Q) with 12 cases (92.3\%) and one case $(7.6 \%)$ with mutation in heterozygosis in exon 3 (p.P46L). The mean age at diagnosis was 27.92 years (IR $12-55$ years). 5 patients showed simultaneous genetic variants in other genes related to autoinflammatory syndromes. Signs and/or symptoms were myalgia and elevation of acutephase reactants with 12 patients (86\%) followed by fever and joint symptoms (arthralgias and/or arthritis) with 11 patients $(79 \%)$ were the most frequent. 2 patients (14\%) had conjunctivitis. 9 patients (64\%) presented cutaneous involvement. 2 cases (14\%) presented lymphadenopathy. Regarding treatment, 5 patients $(36 \%)$ had received treatment with biological therapy (anti-IL-1 or anti-TNF) and another 5 patients $(36 \%)$ had used colchicine. The corticoids were used in 6 patients (43\%)

Conclusion: The TRAPS syndrome is a clinical entity to consider when making a differential diagnosis in patients with suspected autoinflammatory syndrome, that present fever, acute phase reactants elevation, arthromyalgia and its confirmation diagnosis is with genetic test

Disclosure of Interests: None declared

DOI: 10.1136/annrheumdis-2019-eular.7036

\section{THU0583 EXPERIENCE OF ANAKINRA AND CANAKINUMAB IN PATIENTS WITH COLCHICINE-RESISTANT FAMILIAL MEDITERRANEAN FEVER AND COMPLICATED WITH AMYLOIDOSIS}

Ali Şahin ${ }^{1}$, Mehmet Emin Derin ${ }^{2}$, Fatih Albayrak ${ }^{2}$, Burak Karakaş2. ${ }^{1}$ Sivas Cumhuriyet University, Rheumatology-Internal Medicine, sivas, Turkey, ${ }^{2}$ Sivas Cumhuriyet University, sivas, Turkey

Background: Familial Mediterranean Fever (FMF) is a hereditary autoinflammatory disease characterized by recurrent fever and serosal inflammation (1). The goal of FMF treatment is to prevent the attacks and to minimize subclinical inflammation between attacks, and in attacks-free period. Colchicine is a major drug that sine qua non in the treatment of FMF. However, anti-interleukin-1 agents are recommended in colchicine resistant and/or intolerant FMF patients (2).

Objectives: The aim of this study is to evaluate the efficacy of anti-interleukin-1 (anti-IL-1) agents in 54 FMF patients with resistant/intolareted to colchicine or complicated with amyloidosis.

Methods: Between January 2014 and December 2018, fifty four patients who were diagnosed as FMF according to the criteria of Tel-Hashomer that following-up at Sivas Cumhuriyet University Medical Faculty, Rheumatology-Internal Medicine Department were included in to the study.

Results: $25(46.3 \%)$ male and $29(53.7 \%)$ female were included in the study. The median age of the patients was 29 (min:17-max: 60) years and the median age at diagnosis was 18 (min: 3-max: 46) years. Anakinra was used in $34(63 \%)$ FMF patients $(100 \mathrm{mg} /$ day $)$, and canakinumab was used in $20(37 \%)$ patients $(150 \mathrm{mg} / 8$ weeks). 37 cases were resistant to colchicine, 8 were intolerant to colchicine, $9(20 \%)$ cases were comlicated with amyloidosis. 8 patients had renal transplantation. MEFV gene mutations are shown in Table 1. Median duration of anti-IL-1 agent use was 12 months (min:2-max40). 5 patients were resistant to anakinra, 4 patients had side effects which anakinra related. After a median follow up 12 months overall clinical response was\%95 (frequency of attacks $<1 / 6$ months). Median proteinuria decreased from 3850 $\mathrm{mg} /$ day to median $1600 \mathrm{mg} /$ day $(\mathrm{p}=0.04$ ) (Table 2). IL-6 treatment was started in 3 patients because of ineffectiveness of canakinumab. One pregnant patient was followed up with anakinra during pregnancy and there were no problems.

Conclusion: Anti-interleukin-1 agents can be used effectively and safely in the treatment of FMF patients. These agents are especially effective in the treatment of proteinuria due to amyloidosis. Large and long-lasting follow-up studies are needed to evaluate long-term effects of these drugs.

\section{REFERENCES}

[1] Ozdogan H, Ugurlu S. Familial Mediterranean Fever. Presse Med. 2019 Jan 24. pii: S0755-4982(18)30486-X. doi: 10.1016/j.lpm.2018.08.014. [Epub ahead of print]

[2] Seza Özen ve ark. EULAR recommendations for the management of familial Mediterranean fever. Ann Rheum Dis. 2016 Apr;75(4):644-51

Table 1. MEFV mutations in FMF patients

\begin{tabular}{lc}
\hline MEFV Mutations & $\mathbf{n}$ \\
\hline M694V homozygus & $20(37 \%)$ \\
M694V heterozygous & $8(15 \%)$ \\
Compound mutation & $14(26 \%)$ \\
Other mutation & $8(15 \%)$ \\
No mutation & $4(8 \%)$ \\
\hline
\end{tabular}

Table 2. Laboratory Findings of the FMF patients treated with anti-IL-1 agents

\begin{tabular}{lccc}
\hline & $\begin{array}{c}\text { Pre- } \\
\text { treatment } \\
\text { (median) }\end{array}$ & $\begin{array}{c}\text { Post- } \\
\text { Treatment } \\
\text { (median) }\end{array}$ & $\mathrm{p}$ \\
\hline Number of attacks & $>2 / 6$ month & $<1 / 6$ month & $\mathrm{p}<0.05$ \\
ESR mm/h & 33 & 8 & $\mathrm{p}<0.05$ \\
CRP mg/dl & 43 & 4.3 & $\mathrm{p}<0.05$ \\
Proteinuria mg/ & 3856 & 1600 & $\mathrm{p}<0.05$ \\
day & & & \\
\hline
\end{tabular}

Disclosure of Interests: None declared

DOI: 10.1136/annrheumdis-2019-eular.4760

\section{THU0584 RHEUMATOLOGICAL IMMUNE-RELATED ADVERSE EVENTS ASSOCIADTED WITH IMMUNOTHERAPY IN SOLID ORGAN TUMOR. STUDY OF 102 CASES FROM A REFERRAL SINGLE CENTER FOR LAST 4 YEARS}

Lara Sánchez Bilbao ${ }^{1}$, Iñigo González-Mazón ${ }^{1}$, Rosalía Demetrio-Pablo² ${ }^{2}$ José Luis Martín-Varillas ${ }^{1}$, Marina Delgado Ruiz ${ }^{3}$, Isabel Bernat Piña ${ }^{3}$, Belén AtienzaMateo ${ }^{1}$, Monica Calderón-Goercke ${ }^{1}$, D. Prieto-Peña ${ }^{1}$, Almudena García Castaño ${ }^{3}$, Miguel A González-Gay ${ }^{1}$, Ricardo Blanco ${ }^{1}{ }^{1}$ Marqués de Valdecilla University Hospital, Rheumatology, Santander, Spain; ${ }^{2}$ Marqués de Valdecilla University Hospital, Ophtalmology, Santander, Spain; ${ }^{3}$ Marqués de Valdecilla University Hospital, Oncology, Santander, Spain

Background: Immune checkpoint blockade therapy (ICBT) currently is one of the most used therapies against cancer. The activation of the immune system can lead to different immune-related adverse events (irAEs), being the rheumatological side effects among the most common.

Objectives: Our aim was to assess the rheumatological irAEs in patients who received immunotherapy.

Methods: We set up an observational study of patients treated with Nivolumab and Pembrolizumab (anti-PD1), Atezolizumab (anti-PD-L1) and Ipilimumab (antiCTLA-4) for solid organ tumors. All these patients were followed in a single reference University Hospital from March-2015 up to December-2018. The main outcome was to determinate the incidence of rheumatological irAEs.

Results: We studied 102 patients $\left(63^{\pi} / 39\right.$ 우 $)$ with a mean age of 60.6 \pm 9.7 with different solid organ tumors. Only 7 patients $(6.8 \%)$ had a previous diagnosis of an immune-mediated disease: psoriasis $(n=2)$, psoriatic arthritis (1), systemic lupus erythematosus (1), spondyloarthitis (1), rheumatoid arthritis (1) and skin lupus (1) 